\title{
PROSTHETIC MANAGEMENT OF ORAL SUBMUCOUS FIBROSIS: A CASE REPORT AN INNOVATIVE METHOD FOR FABRICATION OF SECTIONAL DENTURES
}

\author{
Sheela kumari, Rathika Rai
}

Department of Prosthodontics, Thai moogambigai dental college and hospital, Dr.M.G.R .Educational and research institute, Chennai, India.

\section{ARTICLE INFORMATION:}

Article History:

Received: 26 March, 2017

Accepted in revised form: 03 July, 2017

Published:1 August, 2017

Corresponding author:

Sheela kumari

E-mail: Sheela_bds@yahoo.co.in

Keyword:

Sectional trays, magnets, precision attachment.

\begin{abstract}
:
Prosthetic rehabilitation of microstomia patients due to oral submucous fibrosis presents difficulties at all stages as the maximal oral opening is smaller than the size of a complete denture. Several techniques have been described for use when either standard impression trays or the denture itself becomes too difficult to place and remove from the mouth. This article describes a different design for the fabrication of maxillary and mandibular sectional trays to enable easier and efficient impression making in a patient with limited oral opening.
\end{abstract}

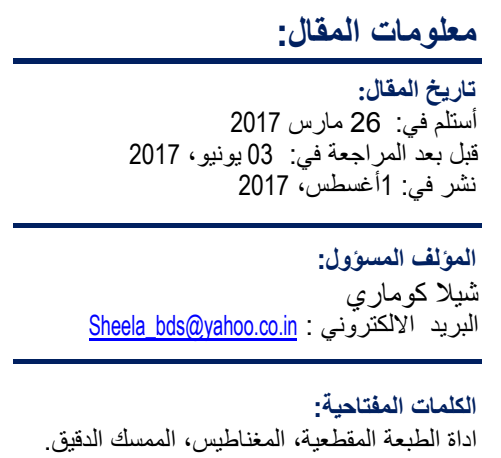

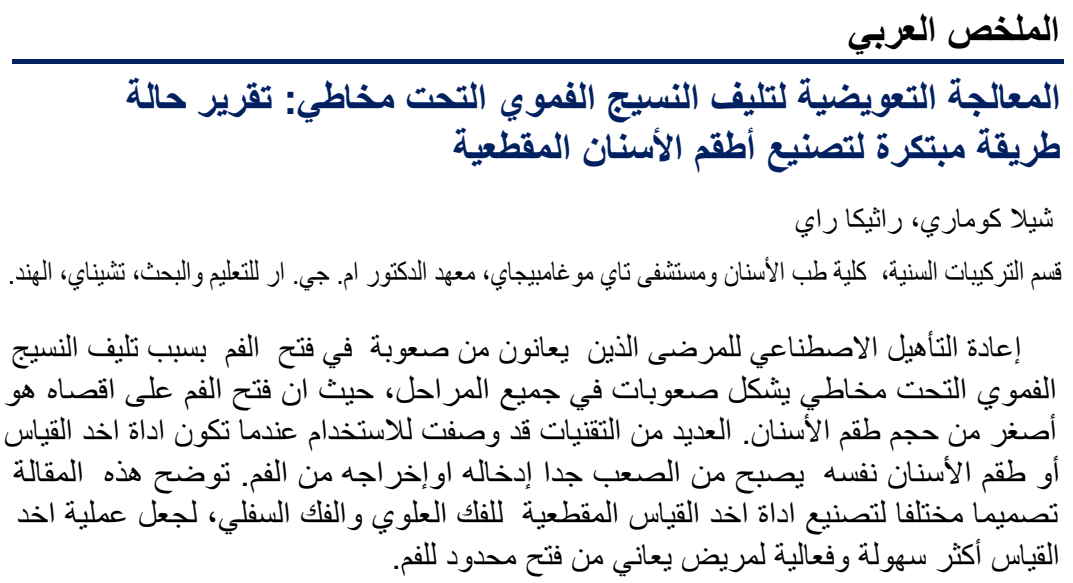

Copyright $\odot$ 2017. LDJ. This is an open access article distributed under the Creative Commons Attribution 3.0 License, which permits unrestricted use, distribution, and reproduction in any medium, provided the original work is properly cited.

Citation:Libyan Dent J 2017, 7: 25520861 -http://dx.doi.org/10.5542/LDJ.v7i0.25520861 


\section{INTRODUCTION}

Oral Submucous Fibrosis (OSMF) is a chronic inflammatory disease that results in progressive juxtaepethelial Inflammatory reaction followed by a fibroelastic change of lamina propia with epithelial atrophy leading to stiffness of oral mucosa, causing limited oral opening (microstomia), burning sensation, difficulty in chewing, swallowing and speaking. ${ }^{1}$ It is associated with genetic predisposition and alterations, infectious and viral agents, carcinogens and immunological factors. It is most commonly related to the habit of tobacco chewing.

Consumption of chilies, deficiency of iron and B complex, smoking, alcohol and tobacco play important role in initiation of disease. Patients with OSMF often complain of burning sensation of the mouth especially when eating spicy food. This is accompanied by vesicles formation, ulceration or recurrent stomatitis with excessive salivation and defective gustatory sensation. The most serious consequences of OSMF is malignant transformation or development of squamous cell carcinoma of affected tissues which occurs in $3 \%$ to $6 \%$ of the cases. ${ }^{2}$

Limited oral opening can also be caused by head and neck radiation, reflex spasm, surgically treated head and neck tumours, microinvasion of the muscles of mastication, connective tissue diseases, fibrosis of masticatory muscles, facial burns, and reconstructive lip surgeries. Hardening of the skin around the mouth causes the oral opening to become limited. ${ }^{3}$ Moreover, fibrosis of the salivary glands results in dryness in the mouth. The different management techniques to aid prosthetic rehabilitation include surgery but this may leads to usual scar formation which further reduce mouth opening. ${ }^{4}$

The literature contains reports on the fabrication of a foldable, posterior section with molar and premolar teeth and a second denture base on which anterior teeth were arranged. 4,5 McCord et al described a maxillary complete denture consisting of two pieces joined by a stainless steel rod with a diameter of $1 \mathrm{~mm}$ fitted behind the central incisors. ${ }^{6}$ Various other components like interlocking segments, ${ }^{7}$ lego blocks, ${ }^{8}$,

9 orthodontic screws ${ }^{10}$ stainless steel post inserted into the tubing, ${ }^{11}$ flexible trays prepared using silicon putty ${ }^{12}$ have been reported.

Prosthetic rehabilitation of these patients presents difficulties right from the preliminary impressions to insertion of the prostheses. This condition hinders conventional prosthetic treatment of edentulous patients. ${ }^{13}$
Particularly the fabrication of complete denture is complicated by the loss of resiliency of tissues, limited tongue movements and the constant adjustments required accommodating the changing periphery. ${ }^{14}$ Various treatment modalities include surgery, ${ }^{15}$ dynamic opening devices called microstomia orthoses and modification of denture design. ${ }^{16}$ This article describes a method for sectional denture for a patient with OSMF where limited mouth opening of oral cavity will not allow the use of conventional complete denture.

\section{CASE REPORT}

A 58 years old female patient was referred to Department of Prosthodontics for replacement of missing teeth. On extra oral examination, their was scar formation on right and left side of the cheeks (Fig 1). The mouth opening measured was $28 \mathrm{~mm}$ (Fig 2). On intraoral examination, the patient had completely edentulous maxillary and mandibular arches and presence of scar on right and left buccal mucosa (Figs 3, 4). On history taking ,patient had the habit of tobacco chewing for past 20 years and she was diagnosed and operated for precancerous oral submucous fibrosis by the Department of Oral Surgery with a nasolabial graft placed on right and left buccal mucosa which resulted in scar formation.

\section{PROCEDURE}

\section{Preliminary impression}

Preliminary impressions were made using silicon putty impression material by hand manipulation. Sufficient amount of silicone putty material was mixed to cover all important anatomic regions of the arch. Well kneaded silicone putty material was adapted into the patient's mouth. After the material set, it was removed from the mouth and any excess material was trimmed with surgical blade. Preliminary cast was poured in dental plaster.

\section{Maxillary arch}

The conventional custom tray with spacer was fabricated, and it was sectioned in the midline using a diamond disc. Magnets are attached on both the sides of the handle which bind to each other by means of magnetic effect which will further stabilize the custom tray anteriorly. Magnets were also placed on the palatal aspect of custom tray which are connected by acrylic extension which provides 


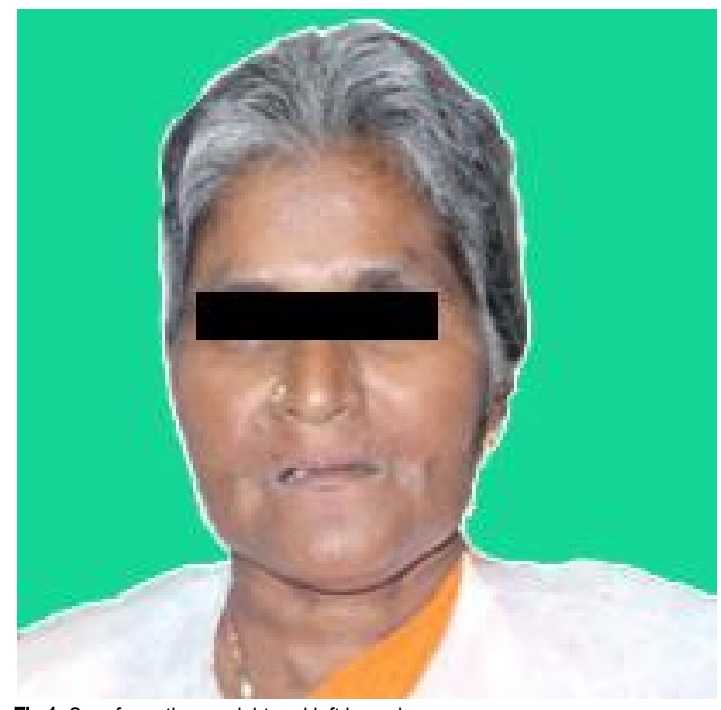

Fig 1: Scar formation on right and left buccal mucosa.

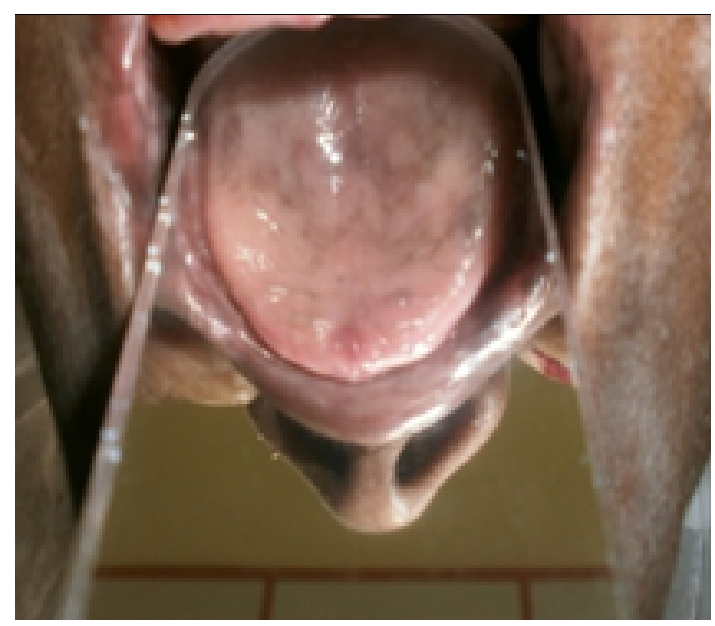

Fig 3: Completely edentulous maxillary arch.

stability on the posterior aspect. One half of the custom tray was border molded sectionally using low fusing stick compound. The other half was then inserted in the mouth for border molding, with the first half still in the mouth. Both the tray halves were removed from the mouth, tempered, and simultaneous border molding carried out.

Final impression made with monophase impression material. Impression was made with the first half of the tray (Fig 5). After removing it from the patient's mouth, the impression material was trimmed so that it was flush with the medial edge of the tray. The impression tray or material that would contact the second half of the tray were lubricated and reinserted in the mouth. The second tray half was loaded with the impression material

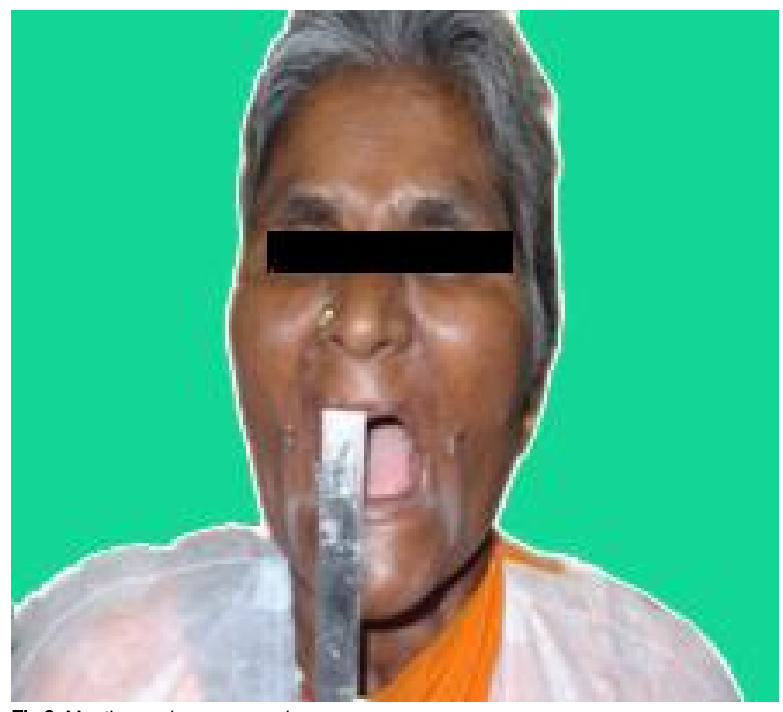

Fig 2: Mouth opening measured.

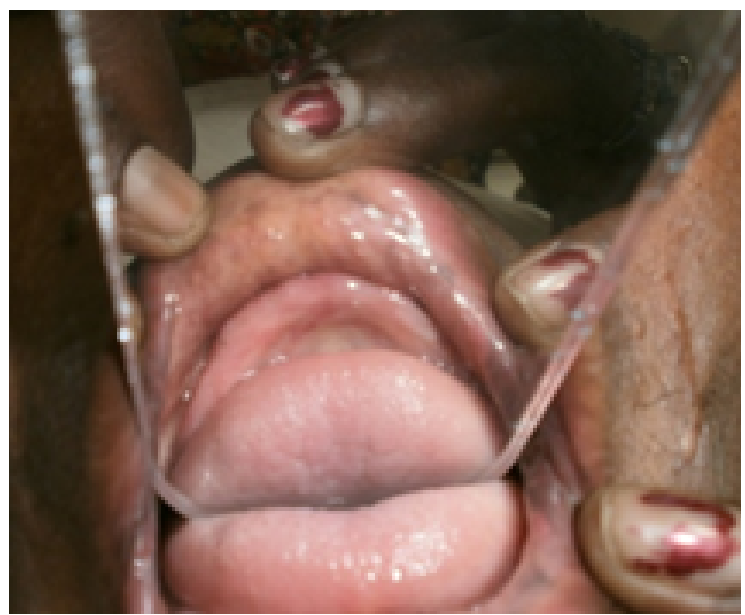

Fig 4: Completely edentulous mandibular arch.

and inserted into the patients mouth. It was ensured that there was proper seating of the two tray halves and the material was allowed to set. The magnets were released and the two halves were removed individually. The tray was then reassembled outside the mouth. The cast was poured after beading and boxing the impression.

\section{Mandibular arch}

The conventional custom tray with spacer was fabricated, and it was sectioned in the midline using a diamond disc. Magnets are attached on both the sides of the handle which bind to each other by means of magnetic effect and this provides stability in the anterior aspect. Posteriorly in right and left molar region, autopolymerising resin stabilized 


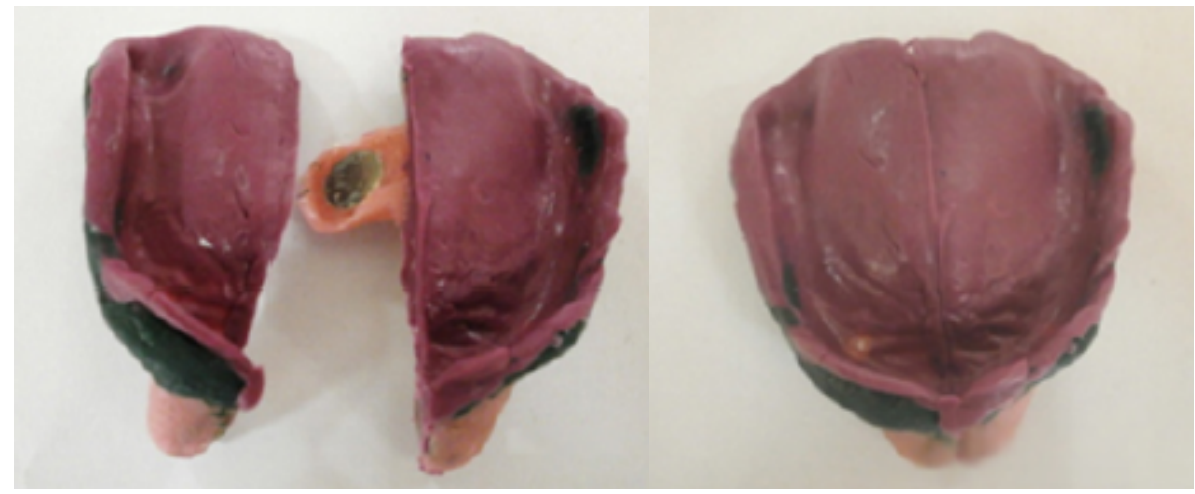

Fig 5: Maxillary split secondary impression with the magnets attached.

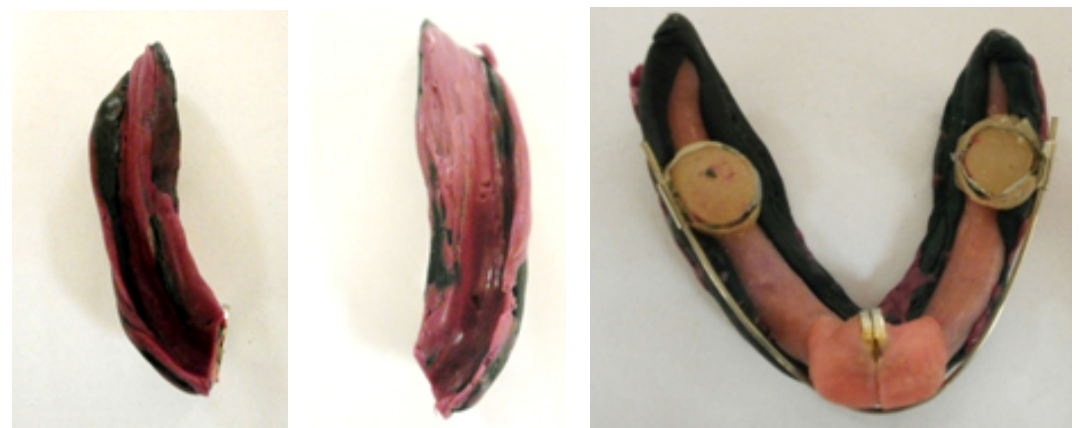

Fig6: Mandibular split secondary impression stabilized by magnets and orthodontic wires.

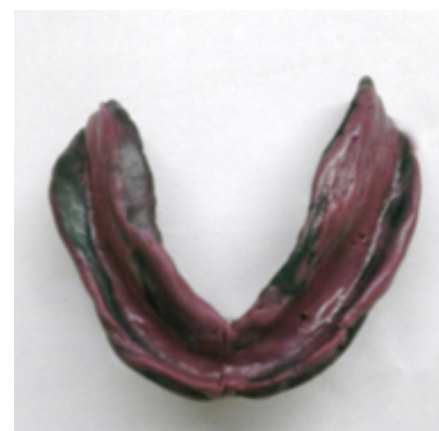

Fig7: Mandibular secondary impression. with the molar band with buccal tube placed on the buccal aspect. These buccal tubes are connected by means of horse shoe shaped 19 guaze wire with the groove placed over the handle for retention of the wire. Final impression made with monophase impression material. Impression was made with the first half of the tray. After removing it from the patient's mouth, the impression material was trimmed so that it was flush with the medial edge of the tray.

The impression tray or material that would contact the second half of the tray were lubricated and reinserted into the patients mouth. The second tray half was loaded with the impression material and inserted in the patient's mouth. The two ends of the tray are connected by means of 19 guaze wire which goes as a retentive end into right and left buccal tubes (Figs 6, 7). The tray was held in place until the material sets. The tray was then reassembled outside the mouth. The cast was poured after beading and boxing the impression.

The denture base are fabricated in both maxillary and mandibular master cast. The magnets on the palatal aspect of maxillary custom tray are replaced by precision attachment (RHEIN 83) in the denture base. Similarly in the mandibular cast precision attachments were placed anterioly on the lingual aspect.
Occlusal rims were made with required measurements. Jaw relation records were obtained and transferred to a mean value articulator with the use of occlusion rims oriented to the established vertical dimension of occlusion, occlusal plane, and the patient's centric relation. Arrangement of artificial teeth and the try- in were carried out in the conventional manner (Fig 8). Before acrylization of the waxed-up sectional denture, the precision attachments were removed. Acrylisation was carried out in a conventional manner. After obtaining sectional dentures the precision attachments were placed by means of surveyor (Figs 9, 10).

At the insertion stage the patient was trained as to how to place and remove the sectional maxillary and mandibular denture. The right segment of the maxillary denture was first inserted into the mouth, then the left segment was inserted to join the right one by means of ball attachment (Figs 11, 12). Patient was given homecare instructions. Evaluation was done at recall visits and adjustments were done as required.

\section{DISCUSSION}

Limited mouth opening in patients is a very common occurrence which presents challenges for fabrication of conventional dentures, hence modified technique have to be used. 


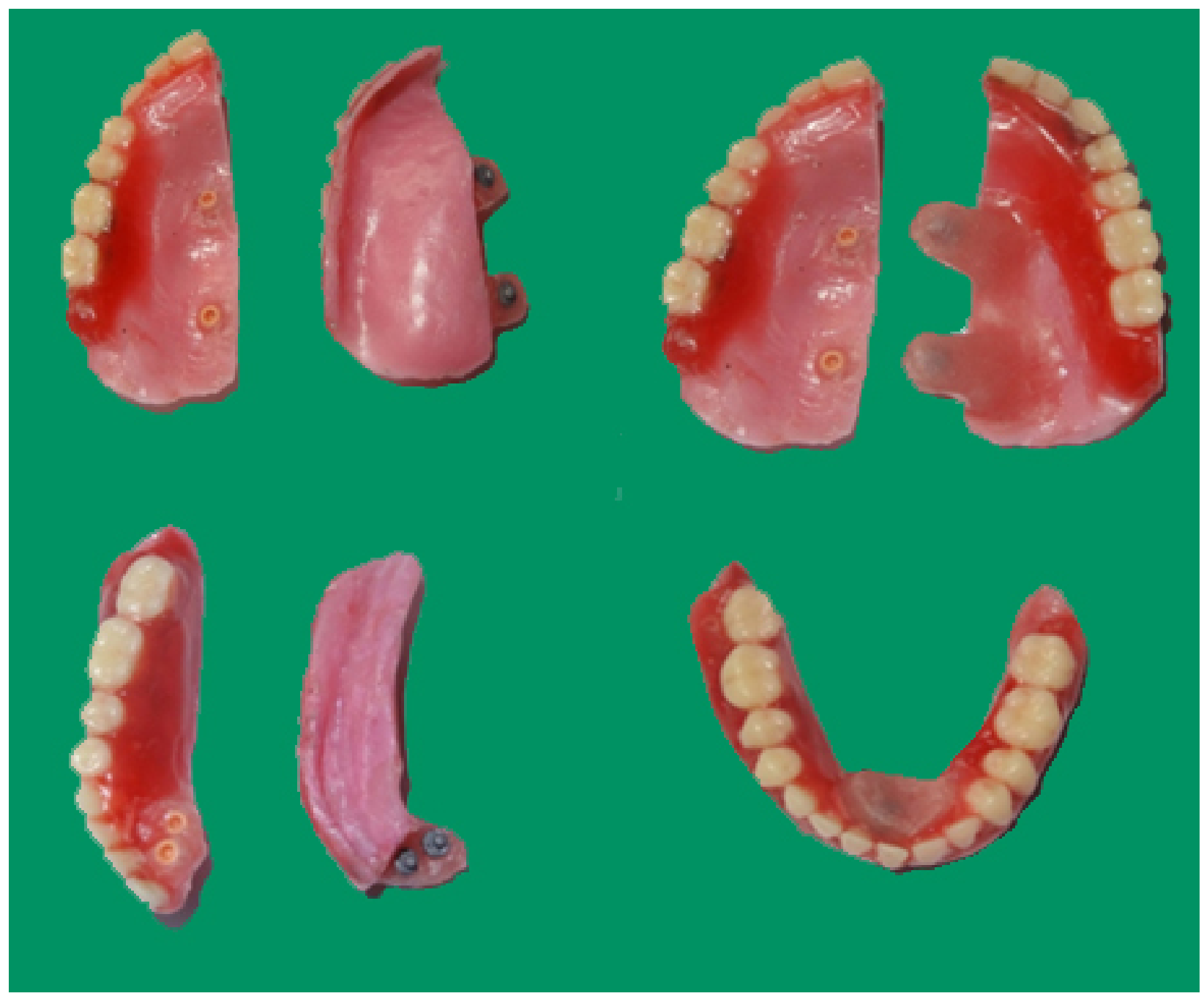

Fig 8: Maxillary and mandibular wax trial showing the teeth arrangement and precision attachment.

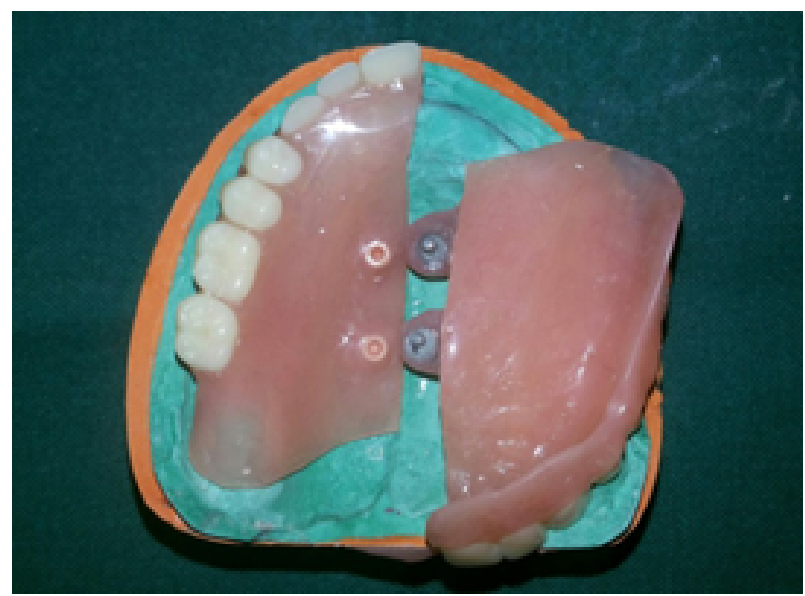

Fig 9: Maxillary sectional denture.

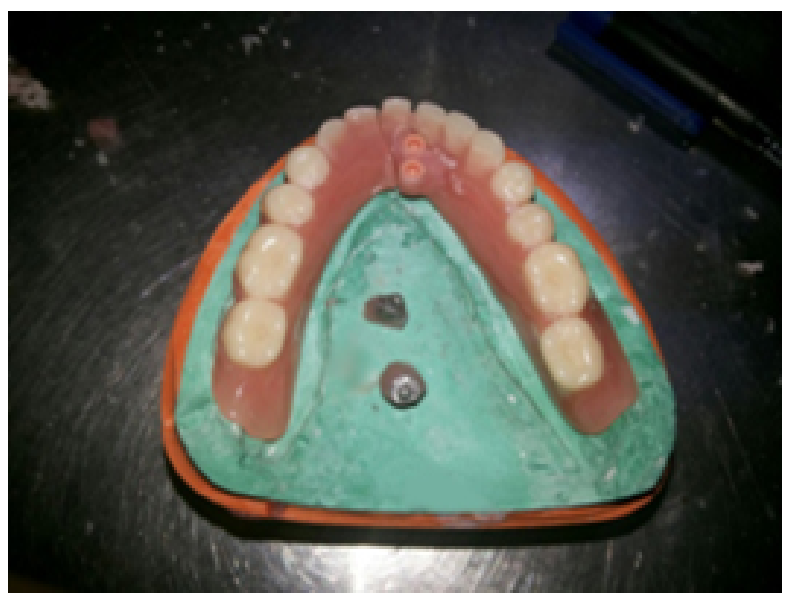

Fig 10: Mandibular sectional denture. 
Various management techniques are described which include use of dynamic bite openers, surgery, and modification of denture design. Yenisy et al described sectioned mandibular denture with a lingual hinge placed at the midline. ${ }^{17}$ The first commissural splint was suggested in 1975, for the management of burns to the lip, which provide resistance to scar contraction to prevent microstomia. ${ }^{18}$ In the year 1983 Naylor and Manor et al described an oral augmentation exercise to increase the vertical opening in microstomia patients by placing a small bundle of tongue depressor between the occlusal surface of the dentures or the natural dentition. ${ }^{13}$ Robert .J.Luebke described sectional stock tray system for making preliminary impressions. The advantage of this system was improved fit of the tray for the edentulous arches because the two halves were fitted to each side of the arch providing better anatomical adaptation. ${ }^{9}$

In the year 1989 McCord et al described a complete sectional denture for microstomia patients which was designed in 2 halves, where both halves were joined together by stainless steel post. ${ }^{7}$ Whale at el in 1992 described a mandibular swing lock complete denture which incorporates a cast Chromium framework with a lingual hinge and a conventional labial swing lock. ${ }^{19}$

Use of microstomia orthoses to expand the oral opening has also been explained as a conservative mode for managing patients with microstomia. ${ }^{3}$ Sectional collapsed complete denture as described by Watanabe uses lingual and palatal midline hinges and a cast iron -platinum magnetic attachment, there are various commercially available magnetic attachment systems which can be used in clinical dentistry for treatment of patients with limited mouth opening. ${ }^{20}$ Sectional collapsed denture using Co-Cr-Mo alloy was suggested by Geckili et al in $2005 .^{5}$

However, with careful treatment planning and prudent designing, the use of either sectional impression techniques and /or sectional dentures many of apparent clinical difficulties can be overcome. Simplified sectional tray design and ease of fabrication are the major advantages of this case report. The advantage being precise nature, easy replacement. The disadvantages include additional time, labour, cost, technique sensitive.

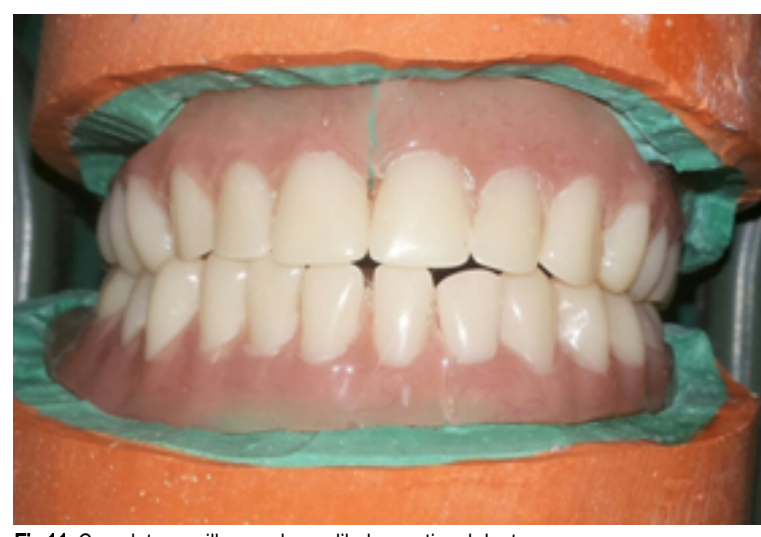

Fig 11: Complete maxillary and mandibular sectional dentures.

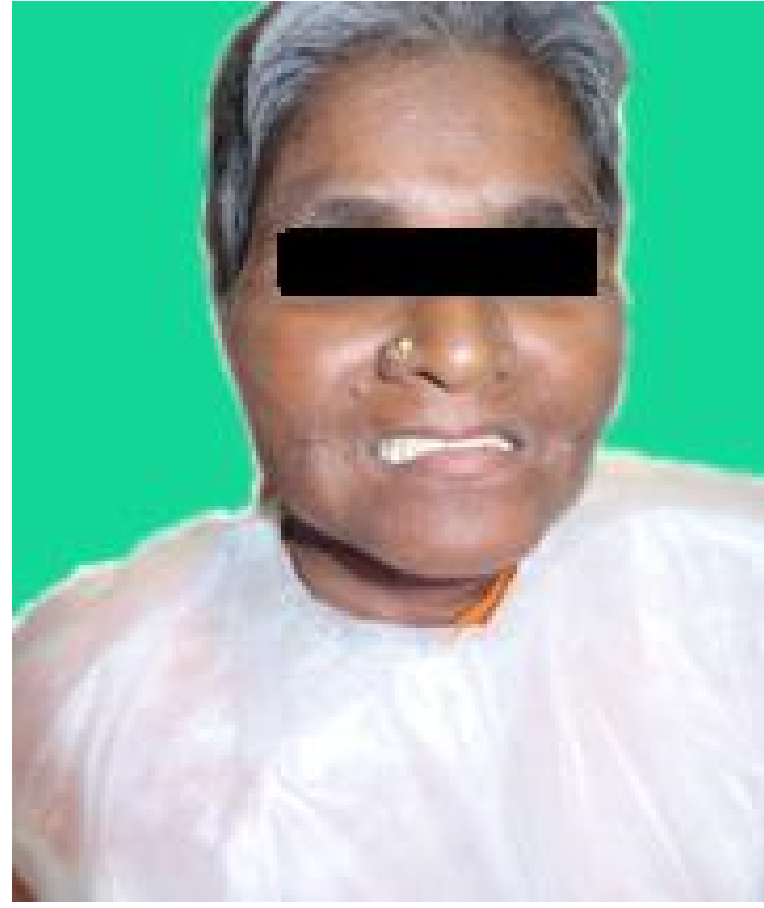

Fig 12: Complete maxillary and mandibular sectional dentures in the patient mouth..

\section{CONCLUSION}

Thus limited mouth opening remains a challenge for fabrication of complete denture prosthesis. This clinical report described an innovative technique of primary impression, sectional custom tray, sectional denture base, and precision attachment applied to sectional complete denture for an edentulous patient with microstomia. Replacement in case of damage and the precise nature of attachment is one of the greatest advantage of this procedure. However, to determine the long term success of this technique, periodic recall and maintenance is required. 


\section{REFERENCES}

1. Singh L, Bharathi SS, Sudhapalli S, Chopra D, Srivastava V. Managementof a patient with oral submucous fibrosis having restricted mouth opening: a case report. Int. Journal of Clinical Dental Science 2011;2:29-35.

2. Shafer, Hine MK, Levy BM . Shafer's text book of oral Pathology. 6th ed. Elsevier a division of reed Elsevier India Pvt Ltd. 96-100.

3. Benetti R, Zupi A, Toffanin A. Prosthetic rehabilitation for a patient with microstomia: a clinical report. The J Prosthet Dent 2004;92:322-327.

4. Cura C, Cotert HS, User A. Fabrication of a sectional impression tray and sectional complete denture for a patient with microstomia and trismus: a clinical report. J Prosthet Dent 2003;89:540-543.

5. Prithviraj $D$, Ramaswamy $S$, Romesh $S$. Prosthetic rehabilitation of patients with microstomia. Indian J Dent Res 2009;20:483-486.

6. Kumar $P$, Singh HP, Kumar A, Jain $C$. Innovative method for fabrication of sectional impression trays for a patient having microstomia. International Journal of Dental Clinics 2012:4:57-58.

7. McCord JF, Tyson KW, Blair IS. A sectional complete denture for a patient with microstomia. J Prosthet Dent 1989;61:645-647.

8. Winkler $S$, Wongthai $P$, Wazney JT. An improved split denture technique. J Prosthet Dent 1984;51:276-279.

9. Luebke RJ. Sectional impression trays for a patients with constricted oral opening. J Prosthet Dent 1984;52:135-137.

10. Suzuki Y, Abe M, Hosoi T, Kurtz KS. Sectional collapsible dentures for partially edentulous patients with microstomia. J Prosthet Dent 2000;84:241-244.
11. Mifezaliaen A. Use of orthodontic expansion screws in fabricating sectional custom tray. J Prosthet Dent 2000;83:474-475.

12. Whisitt JA, Battle LW. Technique for making flexible impression trays for microstomia patients. J Prosthet Dent 1984;52:608-609.

13. Naylor WP, Manor RC. Fabrication of a flexible prosthesis for the edentulous scleroderma patient with microstomia. J Prosthet Dent 1983;50:536-538.

14. Ichimura K, Tanaka T. Trismus in patients with malignant tumours in the head and neck. J. Laryngol Otol 1993;107:1017-1020.

15. Khan Z, Banis JC Jr. Oral commissure expansion prosthesis. J Prosthet Dent 1992;67:383-385.

16. Al-Hadi LA. A simplified technique for prosthetic treatment of microstomia in a patient with scleroderma: A case report. Quintessence Int 1994;25:531-533.

17. Yenisey M, Kulunk T, Kurt S ,Ural C. Prosthodontic management alternative for scleroderma patients. J Oral Rehabil 2005;32:696-700.

18. Bedard J, Thongthammachat S, Toljianic JA. Adjunctive commissure splint therapy: A revised approach. J Prosthet Dent 2003;89: 408-411.

19. Wahle JJ, Gardner LK, Fiebiger M. The mandibular swing lock complete denture for patients with microstomia J Prosthet Dent 1992;68:523-527.

20. Watanabe I, Tanaka Y, Ohkube C, Miller AW. Application of cast magnetic attachments to sectional complete dentures for a patient with microstomia. J Prosthet Dent 2002;88:573-577. 